\title{
Effect of T4 and T6 Treatment on Electrochemical Corrosion Behavior of GW103K Magnesium Alloy
}

\author{
Tao Jin ${ }^{1}$, Shuang $\mathrm{Yu}^{2}$, Shengzhi Liao ${ }^{1}$, Ruiling $\mathrm{Jia}^{2, *}$, Wen $\mathrm{Ma}^{2}$, Feng Guo ${ }^{2}$ \\ ${ }^{1}$ China Special Vehicle Research Institute, Aviation Key Laboratory of Science and Technology on \\ Structural Corrosion Prevention and Control, Jingmen 448035, Hubei, P. R. China \\ ${ }^{2}$ School of Materials Science and Engineering, Inner Mongolia University of Technology, Inner \\ Mongolia Key Laboratory of Thin Film and Coatings Technology, Hohhot, 010051 PR China \\ *E-mail: jr1014014@163.com, jintao52020372@126.com
}

doi: $10.20964 / 2021.01 .39$

Received: 4 September 2020 / Accepted: 29 October 2020 / Published: 30 November 2020

GW103K (Mg-10Gd-3Y-0.4Zr) alloy can achieve better strength and elongation through precipitation hardening method. The precipitation sequence of the alloy has been identified as SSSS (cph) $\rightarrow \beta^{\prime \prime}(\mathrm{D} 019)$ $\rightarrow \beta^{\prime}(\mathrm{cbco}) \rightarrow \beta 1(\mathrm{fcc}) \rightarrow \beta$ (bcc). In present work, the corrosion behavior was evaluated for the GW103K alloy under as-cast, solution treatment (T4) and aged treatment (T6) conditions, and the corrosion mechanism of the alloy after over-aging treatment (193h and 500h) was discussed. Electrochemistry impedance test results showed that the corrosion resistance of the alloy after T6-treated for 193h was the highest. The dissolution of $\mathrm{Mg}_{24}(\mathrm{Gd}, \mathrm{Y})_{5}$ phase led to severe localized corrosion on the as-cast alloy. The localized corrosion of the T4-treated alloy was inhabited because the micro-galvanic coupling between the $\mathrm{Mg}_{24}(\mathrm{Gd}, \mathrm{Y})_{5}$ phases and the matrix was reduced, which was attributed to the volume fraction of $\mathrm{Mg}_{24}(\mathrm{Gd}, \mathrm{Y})_{5}$ greatly decreased. Improved corrosion resistance of aged alloys could be attributed to the corrosion pits produced by the dissolution of the nano-scale $\beta^{\prime}$ phase were tiny and uniform, which led to the corrosion products on the surface more compact. However, slightly lower of corrosion resistance for the T6-500 $\mathrm{h}$ alloy was attributed to the spacing of the reticular structure of $\beta^{\prime}$ phase became wider and some of them transformed for $\beta$ phase $\left(\mathrm{Mg}_{24}(\mathrm{Gd}, \mathrm{Y})_{5}\right)$, the local corrosion was enhanced again.

Keywords: Mg alloy; over-aging treatment; corrosion; electrochemistry

\section{FULL TEXT}

(C) 2021 The Authors. Published by ESG (www.electrochemsci.org). This article is an open access article distributed under the terms and conditions of the Creative Commons Attribution license (http://creativecommons.org/licenses/by/4.0/). 